\title{
El comercio inmigrante y las transformaciones en el Barrio Gótico de Barcelona
}

\author{
Alejandra Toriz de la Rosa \\ Máster en Migraciones y Mediación Social \\ ale_toriz@yahoo.com.mx
}

Resumen: El siguiente artículo forma parte de la investigación que se realizó para la elaboración del Trabajo Final de Máster en Migraciones y Mediación Social. Aborda la llegada de los comercios regentados por extracomunitarios, considerados dentro del sector inmigrante $y$ denominados de alguna forma comercio étnico, ${ }^{1}$ al Barrio Gótico de la ciudad de Barcelona (España) y la competencia de estos comercios con las cadenas multinacionales. Se presentan entonces dos polos de comercio en un mismo barrio, el Gótico, dentro de los cuales los comercios autóctonos están siendo desplazados de forma paulatina por los comercios "tradicionales" del barrio. Palabras clave: comercio étnico, inmigración, multinacional, autóctono.

Abstract: This article is part of the master thesis investigation of the Master in Social Agency and Migration 1. We will talk about the arrive of the outside community stores, owned by immigrants and called Ethnic Commerce in the Gótico neighborhood, in Barcelona, Spain. The competition between this kind of commerce and the multinationals retails are the two opposite poles inside the neighborhood, with disadvantage to the "tradicional" stores that are slowly been displaced or closed. Keywords: etbnic commerce, immigration, multinationals, tradicional.

\footnotetext{
1 Lamentablemente, durante el trabajo de campo no fue posible el contacto, más allá de conversaciones informales, con comerciantes inmigrantes, ya que al escuchar la palabra entrevista abandonaban inmediatamente la conversación. Algunos de ellos mencionaron que sus jefes no les permitían dar información de ningún tipo a nadie. Por eso y otras circunstancias que menciono en el Trabajo Final de Máster, junto con mi asesor, decidí no insistir más en el contacto con comerciantes inmigrantes.
} 


\section{El comercio étnico ${ }^{2}$ y sus definiciones}

El comercio étnico, también conocido como economía étnica, es el ejercido por colectivos inmigrantes que abastece a sus connacionales ante la necesidad de adquirir productos de su país. Estos tipos de comercios tienden a tener una concentración especial en lugares con un alto índice de inmigración como es el caso del Raval en Barcelona o Lavapiés en Madrid (ambas ciudades en España). Tanto el Raval como Lavapiés se caracterizan por ser barrios con población predominantemente inmigrante, pero sobre todo por el gran número de comercios que acaparó este sector, denominado entonces comercio étnico (véanse Moreras, 2007; Cebrián y Bodega, 2002). Abastecen tanto a autóctonos como inmigrantes con carnicerías, colmados, locutorios y tiendas al por mayor de bisutería y ropa.

Actualmente, son diversas las definiciones que se dan a esta actividad económica, definiciones cuya intención es favorecer los estudios sobre los comportamientos de estos negocios. Entre las más retomadas y consideradas por los estudiosos del tema se encuentra la de Buckley Iglesias (2007), quien la define así:

[Aquellas] actividades comerciales gestionadas por los migrantes extranjeros que se dedican a satisfacer una serie de necesidades directas de esos grupos, ya sean las intrínsecas (alimentación, religión, ocio), ya sean las derivadas de su condición de foráneos (comunicación con su tierra, envío de remesas, asesoramiento jurídico, aprendizaje de la lengua); y las que aparecen como consecuencia de su penetración en algunas ramas de la actividad económica (la construcción, la venta al por mayor de productos de importación que abastecen a la venta ambulante, por ejemplo).

(Buckley, 2007: 113)

Así pues, lo "étnico" dentro del ámbito comercial es todo aquello emanado de una colectividad que comparte patrones y prácticas que pueden pertenecer o no al mismo país o región (tal es el caso de los musulmanes, chinos, latinos, andaluces, vascos, gallegos...) y que, como tales, son ajenos al lugar donde se

2 Cabe mencionar que a lo largo de este trabajo no se usa el concepto de comercio extranjero. Aunque hay muchos debates sobre su uso, preferí no utilizarlo para no graficar en los mapas (que se presentan más adelante) a comercios que corresponden a empresas multinacionales o franquicias tales como Starbucks o McDonald's. 
ofrecen. La característica principal de estos comercios es que están regentados por personas que no se identifican con la sociedad receptora, pero que ofrecen sus productos tanto a autóctonos como extranjeros de cualquier nacionalidad. Por otro lado, Pau Serra dice que el comercio étnico es aquella "actividad económica bajo la iniciativa de uno o varios empresarios de origen extranjero y que tiene por objeto la venta de algún producto (bazares, carnicerías...) o servicio (peluquerías, locutorios...) en un local comercial. El comercio étnico es, entonces, un tipo de negocio étnico que se limita a la actividad comercial por cuenta propia (autoempleo); no consiste en la prestación de servicios ni en el empleo por cuenta ajena" (Serra, 2006: 33).

Este es el caso del Raval, también conocido como Ravalistán ${ }^{3}$ (Moreras, 2007), que de alguna forma ha ido transformando su aspecto físico y social en las últimas décadas al recibir a varios miles de inmigrantes de diferentes orígenes, lo que se evidencia en comercios como carnicerías, colmados, locutorios y restaurantes de comida rápida. Monett (2002) describe el caso del Casc Antic en su conjunto (del cual forma parte el Raval), donde los comercios que usualmente eran administrados por autóctonos han ido siendo adquiridos recientemente por el sector inmigrante, tal como se puede observar en vías como la calle Princesa. Otro ejemplo, también barcelonés, es la calle Trafalgar, donde la mayoría de los comercios textiles que pertenecían a catalanes ahora son regentados por chinos.

Para continuar, otra perspectiva analítica es la de Alejandro Garcés (2011), quien dice que el comercio étnico es:

La configuración de un proceso económico que se cierra sobre sí mismo, un proceso en que tanto capital, trabajo y mercancías son puestos en circulación por parte de unos empresarios de origen extranjero, y que apuntan a proveer de un conjunto de bienes y servicios para un grupo étnico o migrante. Así, podría entenderse que la economía étnica es un tipo de economía que se distingue por la fijación de una identidad cultural de quienes son titulares de estos negocios y su potencial clientela.

(Garcés, 2011:2)

3 Este término coloquial designa al barrio del Raval debido a que en las últimas décadas el paquistaní es el colectivo extranjero más numeroso de este barrio de Barcelona. 
Garcés toma en cuenta de cierta forma los aspectos culturales que se enfocan en la venta de producto. Sin embargo, también debe tenerse en cuenta que los contextos bajo los cuales se desarrollan estos comercios los obliga a no permanecer estáticos, sino, por el contrario, a buscar cada vez más nuevas alternativas comerciales, dirigiéndose a lo que más atrae al comprador. Es decir, estaríamos ante una especie de, por así llamarla, adaptación para la sobrevivencia del negocio. Esa es la diferencia que marco en este texto. Es decir, la polaridad del comercio en el Raval radica en la orientación clientelar, que, a diferencia del comerciante del Gótico, procura mantener la clientela sin cambiar el tipo de producto que ya ofrecía el autóctono con anterioridad.

La ubicación espacial del negocio étnico depende de diferentes factores, entre ellos, el tipo de producto que se ofrece, a quién se dirige ese producto y el número de peatones que transitan. Así, los casos más comunes como las peluquerías, los locutorios y los colmados están ubicados en zonas donde habita la población inmigrante. Y los comercios de souvenirs, ropa, calzados y venta al por mayor prefieren espacios mucho más transitados por el público turista. El patrón que sigue la ubicación espacial del comercio étnico también varía de acuerdo con su oferta; mientras que algunos de los negocios de inmigrantes se concentran preferentemente en mercados situados en nichos marginales, otros lo hacen en las zonas más concentradas. Todo depende del poder económico del empresario étnico. Sin embargo, es importante resaltar que un comercio étnico no sería posible si no contara con recursos, es decir, con los elementos que componen su capital. Aunque, a decir verdad, existen diferentes mitos alrededor de cómo se adquiere el financiamiento de los negocios étnicos (como es el caso de los chinos, hindúes y pakistaníes) (véase Valenzuela, 2010).

Otra de las características que se les atribuye a los negocios étnicos gira en torno al tipo de contacto social que se genera con el resto de la población, ya que se considera que los negocios de consumo muchas veces se convierten en determinado momento en centros de reunión de distintos colectivos étnicos, como es el caso de las carnicerías halal o de los locutorios (Solé, Parella y Cavalcanti, 2007; Monnet, 2006). En cambio, los comercios de souvenirs, ropa/accesorios y bisutería son espacios donde la interacción es mucho más esporádica con el comprador y que no se convierten en un punto de reunión con el resto de la población, sin descartar la convivencia entre comerciantes. 
Por lo tanto, defino el comercio étnico como aquellas unidades económicas encabezadas y atendidas principalmente por inmigrantes que ofrecen productos tanto a connacionales como a autóctonos y turistas, siempre con la intención de mantener y/o ampliar su público.

\section{El comercio étnico en el Barrio Gótico de Barcelona ${ }^{4}$}

El Barrio Gótico se ubica en el distrito de Ciutat Vella (véase mapa 1). Este distrito destaca por haber acogido buena parte de la población migrante que ha llegado a Barcelona; en la actualidad alberga el mayor porcentaje de residentes de nacionalidad pakistaní, marroquí, dominicana y filipina, principalmente. La nacionalidad más representativa es la pakistaní, que, de acuerdo con las estadísticas del Ayuntamiento de Barcelona, en 2009 estaba constituida por 5.784 pakistaníes empadronados en Ciutat Vella, lo que representaba un 32,6\% de la población inmigrada; para el 2011 se habían empadronado 6.611 personas de esta misma nacionalidad y en enero del 2013 se contabilizaban un total de 7.272 pakistaníes en el distrito, lo que representa un considerable aumento del colectivo.

\section{Mapa 1. Barrios del distrito de Ciutat Vella de Barcelona}

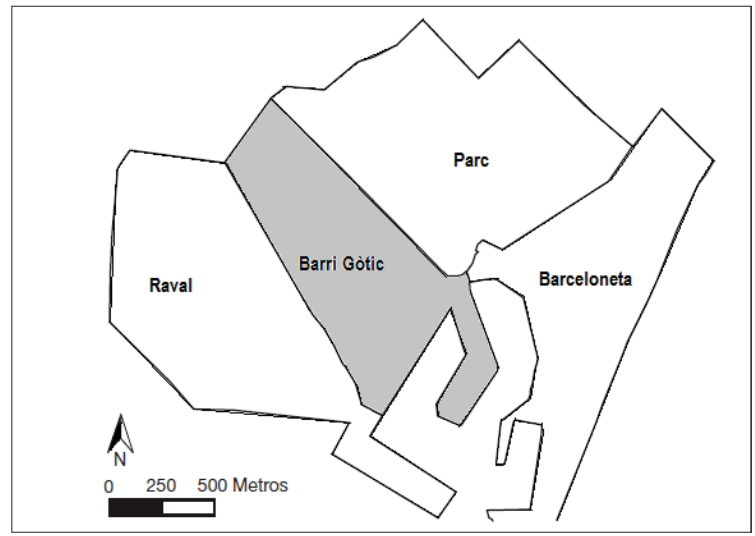

Fuente: mapa extraído de Serra (2006), área sombreada de elaboración propia.

4 Se puede consultar la etnografía completa realizada para el Trabajo Final de Máster en Migraciones y Medicación Social titulado "Las transformaciones comerciales del barrio Gòtic de Barcelona", de Alejandra Toriz de la Rosa. 
El porcentaje de población inmigrante se puede apreciar tanto en el aspecto comercial como en el residencial, ya que en los últimos años el Barrio Gótico ha sido abandonado poco a poco por la población autóctona para abrir la puerta a la inmigración, al turismo y, sobre todo, a quienes están de paso; esto incluye a los jóvenes profesionistas y a quienes buscan espacios de ocio en este tipo de zonas transitadas.

Se le dio el nombre de Barrio Gótico en las décadas centrales del siglo xx, ya que tradicionalmente el espacio era conocido como barrio de la Catedral. La estructura del barrio permaneció casi intacta hasta el siglo xix, cuando se derriban las antiguas murallas medievales y los cementerios parroquiales se transforman en plazas públicas. A lo largo de los siglos XIX y xx experimentó diversas modificaciones, entre ellas la apertura y el ensanche de calles como las de trazado tradicional - Ferran y Sant Jaume - y las nuevas vías del Plan Cerdà que se abren en 1921 — como la Via Laietana_, rompiendo el trazado medieval que dividía el casco antiguo, planteadas principalmente para aspectos como la conservación y puesta en valor de los elementos históricos. Se proponía unificar el estilo de las construcciones y los edificios del barrio en un "verdadero Barrio Gótico", propuesta planteada por grupos artísticos, empresariales y políticos, pero sobre todo por Ramón Rucabado; estos exigían la eliminación de las viviendas degradadas de la zona y sustituirlas por construcciones neomedievales, utilizando para ello los materiales antiguos.

El Barrio Gótico se planteó con la idea de componer un conjunto con materiales antiguos en los alrededores de la catedral que al mismo tiempo se relacionaba con las propias obras de la fachada de este edificio, por lo que durante el siglo xix la burguesía barcelonesa propuso la finalización de su fachada, que había estado pendiente desde el siglo xv. Ello suscitó debates artísticos sobre cómo debía terminarse la fachada de la catedral:

Por un lado, representaba la necesidad de reapropiarse de los signos de identificación colectiva, ahora exhibidos como símbolos nacionales y, por otro, significaba embellecer la ciudad mediante la monumentalización de su principal elemento histórico, ofreciendo una imagen acorde con la importancia de la urbe y su riqueza.

(Cócola, 2011) 
Estas transformaciones urbanas contribuyeron en gran medida al auge del comercio en el barrio, por lo que ha tenido una transición como muchos otros lugares de la ciudad de Barcelona; ello se ha visto reflejado sobre todo en los últimos treinta años cuando comenzaron las reformas en este barrio. Sin embargo, el comercio comenzó a decaer durante la década de 1990, cuando una crisis de los comercios minoristas, también conocida como la crisis del pequeño comercio, obligó a cerrar, entre los años 1995 y 2001, a por lo menos 665 de estos pequeños comercios. Especialmente afectado fue el sector de la alimentación y del tabaco (Nolla, 2010; Serra, 2006).

Los factores que han influido para que esta transformación comercial se haya dado con el paso de los años, especialmente en el Barrio Gótico, están relacionados con el diseño de una ciudad que es capaz de atraer diferentes tipos de visitantes que se interesaran por la historia y el patrimonio monumental. Es verdad que los comercios son una fuente de vida en los centros de la ciudad; si esta carece de comercios, también carece de ambiente, es decir, de atracción turística, pues a la gente le gusta comprar, pasear y combinar la historia con lo comercial.

Por otro lado, los productos de moda también forman parte importante del proceso de transformación comercial, pues los compradores pueden variar de acuerdo con el tipo de oferta y las tendencias comerciales se acercan a ellas cuando notan que algún producto resulta atractivo; este fue el caso de los sombreros mexicanos, que hoy en día están fuera del mercado por el desacuerdo de la población barcelonesa, que rechazaba que un sombrero mexicano se considerara un souvenir catalán, por lo que se diseñaron nuevos productos relacionados con monumentos y personalidades que representaban mejor la identidad barcelonesa y catalana, como el arquitecto modernista Antoni Gaudí (por mencionar algún ejemplo). También se actuó políticamente y en el 2008 el Ayuntamiento de Barcelona suspendió las licencias para abrir tiendas de souvenirs turísticos en el distrito de Ciutat Vella y vetó la ampliación de la superficie de los negocios de este tipo ya existentes. Esta medida de suspender la concesión de más licencias se planteó por la alta concentración de estos comercios en las principales calles y arterias comerciales del Barrio Gótico, especialmente alrededor de la Rambla. La finalidad, según el Ayuntamiento de Barcelona, era "proteger los impactos negativos en el paisaje urbano, los entornos urbanos de especial interés, el pa- 
trimonio arquitectónico y monumental, los entornos culturales y el derecho de los residentes al mantenimiento de su calidad de vida” (Nolla, 2010).

Por otro lado, en el Barrio Gótico también hay comercios de todo tipo, desde locutorios hasta joyerías; pero, ciertamente, la ubicación de estos comercios varía debido al tipo de público a quien se dirige el producto. Así, no hay locutorios en la calle de la Portaferrissa, pero sí en la calle N'Anglà, que es menos transitada por el turismo y sobre todo está "alejada" de lo considerado como turístico, si bien al mismo tiempo es paso de entrada a las viviendas del barrio.

De este modo, la lectura del espacio urbano en Ciutat Vella que elaboran estos comerciantes/empresarios a la hora de ubicar sus espacios comerciales nos recuerda que toda zona urbana es definida por su funcionalidad y su uso. En las ciudades hay zonas donde se concentran las actividades productivas o de servicios, las instituciones administrativas, los locales de ocio y, evidentemente, los espacios comerciales. En este sentido, habría que recordar que, paradójicamente, Ciutat Vella concentra uno de los índices comerciales más elevados de toda la ciudad, pero, al mismo tiempo, cuenta con zonas en las que el tejido comercial es casi inexistente. Asimismo, este barrio cuenta con algunos importantes ejes urbanos (Ramblas, Via Laietana, calles Ferran y Princesa) que han propiciado esta concentración comercial (Moreras, 2007: 140).

Un recorrido por el Gótico permite apreciar las diversas polaridades en determinadas calles, que de alguna forma están siendo privilegiadas o segregadas por las políticas urbanísticas; cabe mencionar que estas políticas están fuertemente orientadas a la gentrificación, la cual comporta que la población residente esté siendo desplazada a las periferias al convertir el barrio en una zona privilegiada (véase Sargatal, 2001).

Como parte de la investigación, se tomó una muestra representativa de las calles más transitadas del Barrio Gótico. Ciertamente, la Rambla es la más transitada y sirve de conexión entre el Raval y el Gótico y cuenta también con una alta presencia de comercio étnico. Sin embargo, el Gótico continúa siendo un barrio distinguido por los comercios "tradicionales". Las calles son Portaferrissa, Ferran, Boqueria y Call (véase mapa 2). 


\section{Mapa 2. Portaferrissa, Boqueria, Call y Ferran}

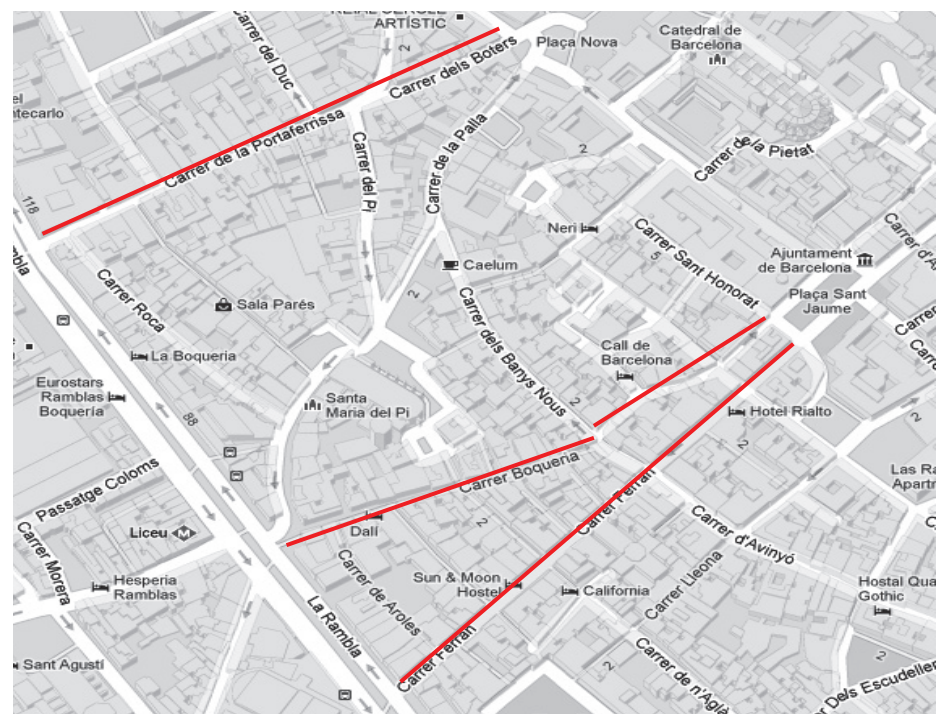

En rojo, las calles Portaferrissa, dels Boters, Boqueria, Call y Ferran. Fuente: Google Maps.

Estas calles reúnen, en conjunto con sus callejones adyacentes, comercios con una gama de productos que intentan quedar fuera de la "homogeneidad" y ofrecer una diversidad en la que lo autóctono/tradicional interaccione con lo comercial y lo turístico. El Barrio Gótico se distingue por dos particularidades: primero, porque en los últimos años los inmigrantes han comenzado a tomar los espacios dejados por los autóctonos; $y$, segundo, porque las cadenas multinacionales compiten con los comercios étnicos en la búsqueda de espacios para una nueva tienda.

Dentro del Barrio Gótico, los comerciantes distinguen dos polos, Gótico Norte y Gótico Sur, ${ }^{5}$ una distinción muy importante en cuanto al tipo de comercio. Mientras que en el Gótico Sur aparentemente se mantiene un comercio dentro del marco denominado "tradicional", en el Gótico Norte se encuentra

5 Entrevista abierta, David Vendrey, Barna Centre, marzo de 2013.

6 Históricamente, el Barrio Gótico se ha caracterizado principalmente por su atracción comercial; sin embargo, delimitar lo que realmente podría ser considerado tradicional no permitiría mostrar claramente cómo se ha ido construyendo esta identidad comercial debido a que Ciutat Vella ha recibido grandes oleadas migratorias a lo largo de su historia. Con todo, para la mayoría de los comerciantes entrevistados, los comercios 
el denominado comercio "nuevo", que en este caso son las cadenas multinacionales. De esta forma, Portaferrissa se encuentra en el Gótico Norte y Boqueria, Call y Ferran en el Gótico Sur. Son cuatro calles que de alguna forma simbolizan una historia comercial del Barrio Gótico, en el amplio concepto del comercio al por mayor y a la venta en general.

La llegada del comercio inmigrante al Barrio Gótico ha ampliado su público a través de franquicias que venden todo tipo de souvenirs de la marca Barcelona dirigidos al turismo, y bisutería orientada principalmente a la población local, con la compra al por mayor. En este tipo de negocios destaca la presencia de comerciantes de la India, Pakistán y China, principalmente. Cabe resaltar que estos negocios también están presentes en otras zonas turísticas de la ciudad. Estos negocios han ocupado poco a poco los espacios que han ido dejando los autóctonos en los últimos cuarenta años. En este sentido, han desaparecido comercios que tenían una tradición en el barrio, es decir, que estaban altamente especializados en la población residente y que atendían las necesidades de quienes vivían ahí. Fenómenos como este desagradan a muchos autóctonos, que evitan pasar por el Barrio Gótico al considerar que no hay motivo alguno que los lleve al barrio.

El desplazamiento de los comercios autóctonos se ha dado por dos factores principales: primero, por la ausencia de población autóctona en el barrio, de modo que en su mayoría ha quedado población inmigrante; y, segundo, por un incremento del turismo (aunque ya lo había antes). Asimismo, cabe destacar las bajas posibilidades de los autóctonos para alquilar espacios, pues los precios van en aumento ante la creciente demanda de las cadenas multinacionales, que cuentan con recursos para alquilarlos; a ello hay que sumar que los inmigrantes sí que pueden competir con las multinacionales pues, a través de financiaciones o préstamos de sus connacionales, cuentan con dinero para alquilar tales espacios.

Entre el 2001 y el 2004, Serra (2006) y Moreras (2007) realizaron estudios sobre el comercio étnico en Ciutat Vella que mostraron que la presencia de este en el Barrio Gótico es mucho menor en comparación con el Raval y el Casc Antic, destacando que en las calles Boqueria, Call y Ferran no representaban un

tradicionales eran aquellos establecidos "desde que tenían recuerdos", y sobre todo aquellos que se dirigían a la gente que vivía en el mismo barrio o ciudad. Así pues, se ha considerado comercio tradicional para este trabajo los comercios que se establecieron antes de la década de 1970, puesto que la década de 1980 representó un momento de transición muy importante en la zona del Barrio Gótico. 
número importante. Sin embargo, en los últimos años se puede apreciar un aumento paulatino de comercios étnicos. Digo paulatino porque, de alguna forma, la llegada de inmigración en los últimos años no ha sido del todo positiva para España, sobre todo si se piensa en la actual crisis económica; tal circunstancia, en cambio, no ha supuesto un problema para los comercios inmigrantes, que han aprovechado los vacíos en estas calles donde los alquileres todavía no son tan altos como en Portaferrissa. La dicotomía de estas calles se puede distinguir claramente en el siguiente cuadro:

Cuadro 1. Tipo de productos frente a tipo de comercio.

\begin{tabular}{|c|c|}
\hline Portaferrissa & Ferran, Boqueria y Call \\
\hline Comercio orientado a la moda & Comercio de venta al por mayor y bisutería \\
\hline Nula presencia de comercio étnico & Amplia presencia de comercio étnico \\
\hline Llegada de cadenas multinacionales & $\begin{array}{c}\text { Llegada de comerciantes sobre todo de } \\
\text { origen indio, pakistaní y chino }\end{array}$ \\
\hline
\end{tabular}

Fuente: elaboración propia sobre la base de las observaciones de trabajo de campo.

La idea de un Barrio Gótico diferenciado en dos polos, Norte y Sur, se refleja en el cuadro anterior; en él se ve con buenos ojos la llegada de las multinacionales, mientras que se rechaza abiertamente el comercio administrado por inmigrantes que mantienen vivo el comercio en el barrio.

El comportamiento del comercio étnico se puede apreciar especialmente en los mapas elaborados por Moreras (2007) y Serra (2006). El primero realiza un mapa en el que muestra el aumento de los comercios étnicos en Ciutat Vella desde el año 1996. En este sentido, entre 1996 y 1999 no se registró presencia de comercios de este tipo en las calles Ferran, Boqueria, Call o Portaferrissa. Sin embargo, en Portaferrissa se registran tres entre 1996 y 1999.

Cabe destacar que los comercios que se señalan en la calle Ferran corresponden en su mayoría a latinoamericanos, mientras que el resto los regentan un marroquí, un pakistaní, un hindú y dos chinos (para más información, véase Moreras, 2007). Por su parte, Serra (2006) elabora un mapa en el que se aprecian menos comercios en las mismas calles, señalando que en Boqueria y Call hay cuatro, tres en Ferran, dos en Portaferrissa y uno en Cucurulla.

Tanto los mapas elaborados por Moreras (2007) como el de Serra (2006) consideraron como una de las bases el Impuesto de Actividades Económicas 
(IAE); ${ }^{7}$ sin embargo, como ellos mismos señalan, estos datos no son del todo fiables ya que muchos de los comerciantes se nacionalizaron y el IAE no revela los nombres de los comerciantes ni su nacionalidad.

En otro mapa de elaboración propia (véase mapa 4), se evidencia un aumento de comercios étnicos; así, por ejemplo, en Boqueria y Call se constatan nuevos comercios de bisutería y minerales regentados por chinos, mientras que en Boqueria y Ferran hay nuevos comercios de souvenirs y textiles (véase mapa 6). Asimismo, están los aparentemente nuevos comercios de textiles de las calles Aroles, Quintana y Baixada de Santa Eulàlia, regentados por hindúes y pakistaníes. Se dice recientemente porque en los mapas elaborados por Serra y Moreras no se registran comercios en esas calles. Mientras que en Portaferrissa sigue sin registrarse ningún negocio, comienza a haber en calles como Petritxol y del Pi (véase mapa 5) y a aumentar considerablemente en la calle Llibreteria (véase mapa 5).

\section{Mapa 3. Comercio étnico en el Barrio Gótico.}

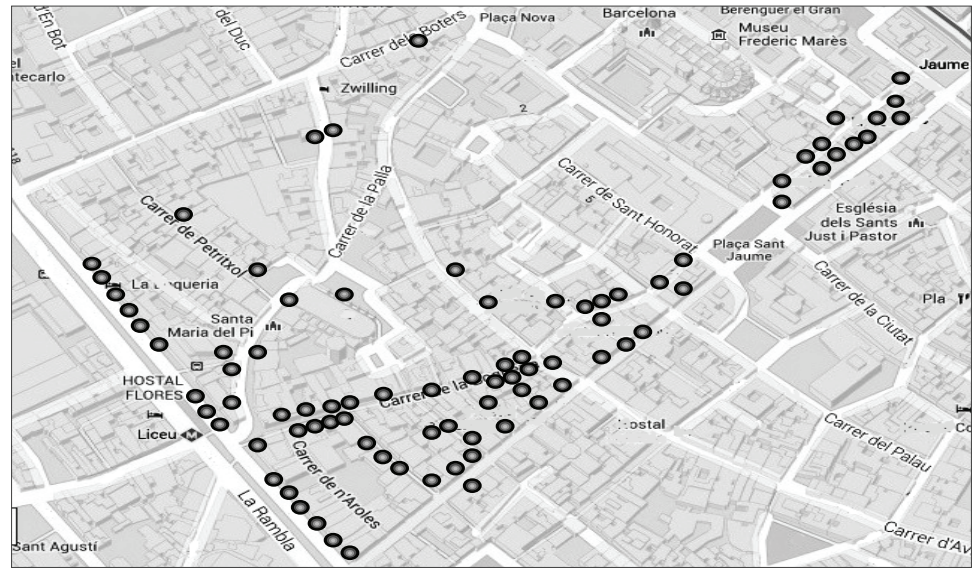

Fuente: elaboración propia sobre la base de entrevistas y datos de trabajo de campo.

7 Serra también se basó en una encuesta que realizó durante el 2004 a comerciantes de Ciutat Vella. 
Mapa 4. Comercio étnico en Ferran, Boqueria y Call.

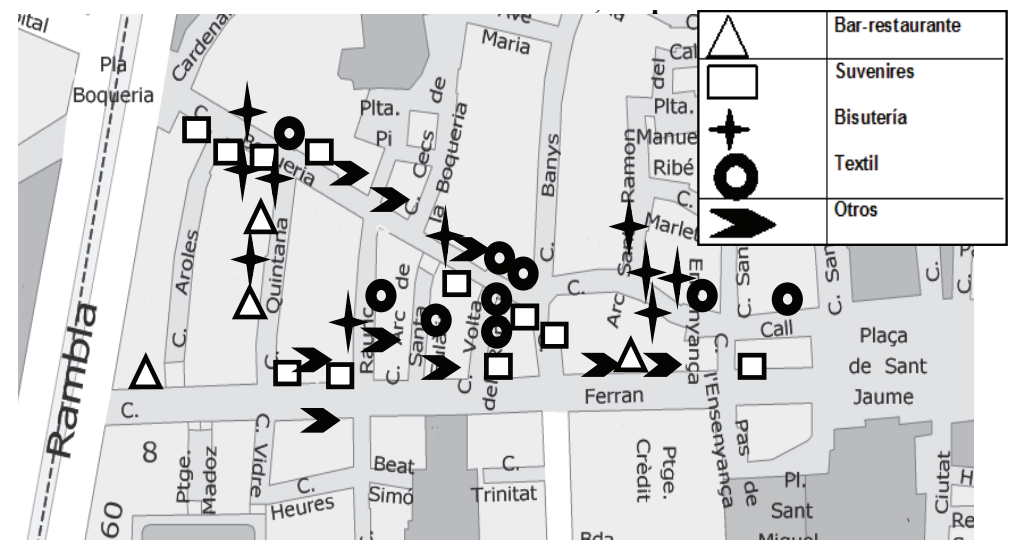

Fuente: elaboración propia sobre la base de entrevistas y datos de trabajo de campo.

Mapa 5. Comercio étnico en Portaferrissa.

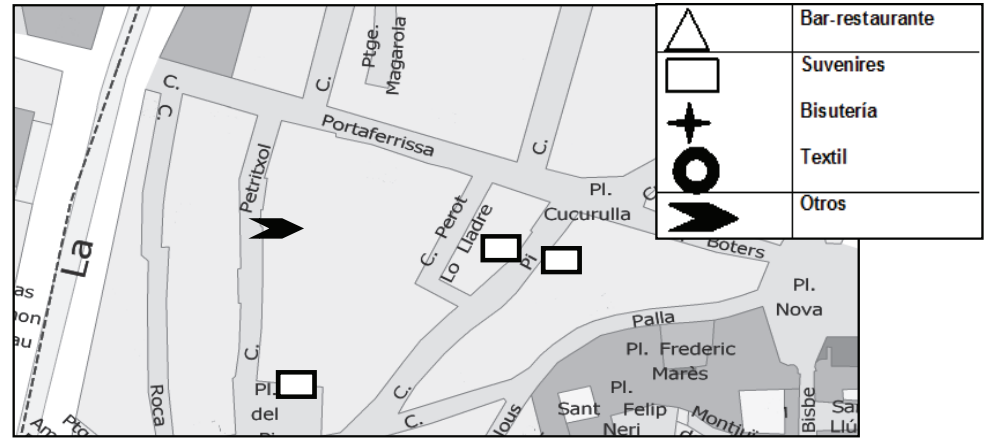

Fuente: Elaboración propia sobre la base de entrevistas y datos de trabajo de campo.

En el mapa 4 se representa una estimación ${ }^{8}$ del tipo de productos de los comercios regentados por inmigrantes (pakistaníes, indios, subsaharianos, ecuatorianos, uruguayos, etc.) en estas calles y sus adyacentes. Mientras que en la calle Portaferrissa no se aprecia este tipo de tiendas, en Petritxol y del Pi, sí (véase mapa 5). Y esto confirma que los alquileres en la calle Portaferrissa son mucho más altos que en el resto de las calles, lo que evita que los comercios regentados por inmigrantes puedan establecerse.

8 Datos recabados a partir del trabajo de campo y las entrevistas. 
Así pues, debe tenerse en cuenta que para este estudio no se están considerando comercios que se ubican en el resto de las calles del Barrio Gótico, como locutorios y tiendas de souvenirs, de bisutería y textiles, lo que no significa que no fueran tomados en cuenta para este trabajo (véase mapa 5). Es el caso de las proximidades de la calle Llibreteria (lo que incluye Sant Jaume, Freneria y Dagueria), con al menos nueve tiendas de souvenirs y un supermercado de reciente apertura. En el 2001 se registró la presencia de cuatro negocios en esas calles, que, de acuerdo con Moreras (2007), pertenecían a latinoamericanos, si bien en la actualidad están regentados por pakistaníes e indios y algunos latinoamericanos.

Algo que llama la atención fuertemente es que el número de comercios que pertenecían a latinoamericanos era muy alto en el año 2001 (Moreras, 2007) en comparación con los comercios de pakistaníes, chinos e indios. En un inicio esto había llevado a plantear el trabajo de otra forma, ya que durante los recorridos de trabajo de campo se veían letreros que decían "Tienda de productos latinoamericanos", mientras que en realidad lo que se vendía eran productos de la India. Sin embargo, con el paso de los meses estos letreros fueron cambiando a "Productos de la India". De ello se deduce que muchos de estos negocios probablemente pertenecían a latinos, especialmente de Perú y Ecuador, y que después fueron adquiridos por estos nuevos comerciantes.

Las condiciones de mercado permiten acceder a este tipo de negocios que están siendo abandonados, y el traspaso en alquiler es el mecanismo principal para acceder a estos, que anteriormente eran regidos por autóctonos o incluso por otros comerciantes extranjeros. En este sentido, es una práctica habitual que los negocios comerciales sean traspasados de unos comerciantes a otros, aunque no necesariamente del mismo colectivo inmigrante (Moreras, 2001). De este modo, los comercios inmigrantes se adaptan a la demanda, sea cual sea la ubicación, porque las comparaciones entre el comercio en el Raval con el comercio en el Gótico muestran claramente cómo las políticas públicas crean etiquetas barriales en las que está permitido abrir algún negocio y el tipo de producto que se va a ofrecer, evaluando si cumple con los estándares de calidad o no propios del barrio. 
En algunos casos ha habido algún tipo de conflicto sobre todo cuando ha habido avalanchas o entradas en masa o en bloque; entre el comercio que ya está establecido muchas veces se puede percibir como una agresión el que entre alguien de fuera, pero también depende del tipo de comercio que entre, porque muchas veces, más que al comercio de fuera, lo que no se ve bien es que, pues, entren productos que a veces son de poca calidad o que no aportan un valor añadido respecto al comercio anterior. Entonces a veces sí que puede ser que se confundan estos dos extremos, que se identifique un comercio que es de fuera con un comercio que no es de calidad, cuando no debería ser así, y sí es cierto que ha habido un cierto conflicto, pero tanto desde la Administración como desde aquí se intenta que las cosas, pues, se suavicen, que se entiendan más, que haya más comprensión entre los dos bandos.

(Entrevista BarnaCentre)

En los últimos años, la presencia de comercios orientados a la venta de productos para el turismo ha aumentado considerablemente en el Barrio Gótico. En la última década estos estaban sobre todo concentrados en la Rambla, el paseo más atrayente de Barcelona, que cuenta de igual forma con una alta presencia de comercios multinacionales, autóctonos y comerciantes. La Rambla es la expresión más representativa de la multiculturalidad en el centro de Barcelona, pues es en ella transita población autóctona, turística e inmigrante que camina, comercia, pasea y compra.

Las etnicidades del comercio, en la zona estudiada, se reflejan en los mapas 6 y 7. El número de comercios regentados por chinos fue en aumento, así como el de indios y/o pakistaníes. Por una parte, el comercio de los colectivos chinos se especializa sobre todo en la venta de bisutería; por otra, los indios se especializan en la venta de souvenirs (camisetas del Barça, llaveros, gorras, etc.), alimentos, electrónica, zapatillas deportivas o bisutería. Y el resto de las nacionalidades se especializa en textil y venta al por mayor. 
Mapa 6. Comercio étnico en Ferran, Call y Boqueria.

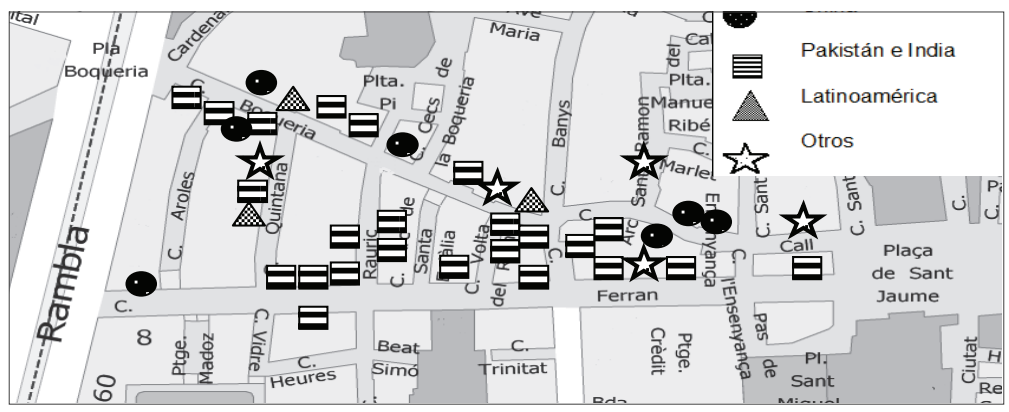

Fuente: elaboración propia sobre la base de entrevistas y datos de trabajo de campo.

\section{Mapa 7. Comercio étnico en Portaferrissa.}

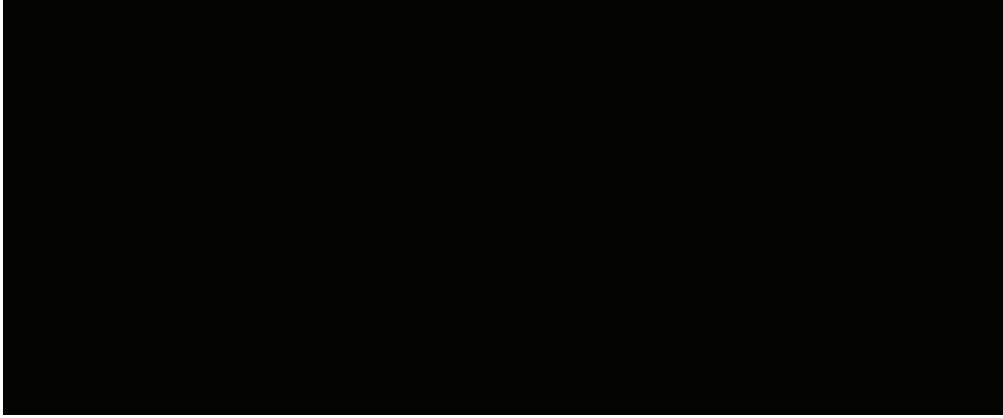

Fuente: elaboración propia sobre la base de entrevistas y datos de trabajo de campo.

Sumado a eso, como ya se ha mencionado anteriormente, la preocupación por los altos costos de alquiler es un tema constante entre los comerciantes, fenómeno que de alguna forma ha contribuido a la incorporación de comerciantes inmigrantes:

Son comercios que abren muchas más horas porque, por ejemplo, nosotros no estamos capacitados para trabajar quince horas en lo mismo y ellos, como pueden, pues aprovechan eso; como pueden invertir en más horas porque trabajan más horas, como no se les controla, es un problema de regulación, creo yo. Por otro lado, se pueden permitir el costo de los alquileres porque, si tú abres una tienda 20 horas, 30 horas o 40 horas más a la semana, obviamente vas a tener más beneficios y te va a permitir pagar lo que cuesta un alquiler por 
aquí, que no lo conozco, pero me imagino que debe de ser de los más caros de Barcelona, porque es por el centro y demás, ¿no? No sé.

(Dependienta de la calle Ferran)

De la misma forma, en torno a estos colectivos siguen circulando historias sobre el pago del alquiler, sobre los horarios de trabajo e incluso sobre los costos privilegiados, lo que sitúa a los inmigrantes como un colectivo poco deseado. Pero estos son mitos que van de boca en boca, mitos que se van reproduciendo y que no hacen sino aumentar el rechazo de otros comerciantes hacia el comercio inmigrante.

Mira, aquí hay de todo, unos, claro, dicen: ¡Es que estos de aquí, estos no pagan impuestos! ¿Cómo que no pagan impuestos? Claro que pagan impuestos, todo el mundo paga los impuestos, eso es un muro que, bueno, salido de los fascistas, PP y compañía, que han siempre... iilos racistas!! Esto es estúpido porque nadie se escapa de los impuestos, incluso a uno que llega aquí se le exigen porque, si no, no se le atiende. Mira, vamos a ver, esa persona tiene tanto derecho como cualquier nacional, esa persona en el momento que esté aquí y compre aquí está pagando sus impuestos porque el IVA no se lo quitarán y, por lo tanto, tiene derecho, así de claro, lo que pasa es que aquí la cosa va como en todos los países, incluso en la rica Alemania.

(Comerciante calle de la Boqueria)

Las historias que se centran alrededor de los comercios inmigrantes no toman en cuenta que son grupos vulnerables que han dejado sus países en busca de otras oportunidades de trabajo, que la mayoría de ellos abandona a su familia y se enfrenta a condiciones precarias de trabajo y vivienda. No se pretende victimizar a los inmigrantes, pues no todos viajan en las mismas condiciones, pero sí debe tomarse en cuenta que los comercios de inmigrantes trabajan para obtener más ganancias y aprovechan los espacios que quedan vacíos para generar la mayor productividad posible. Por ejemplo, en Cataluña es común que los comercios cierren de las 14.00 horas a las 17.00 horas; para los comerciantes inmigrantes son tres horas muertas de trabajo, son tres horas que deben ser aprovechadas, sobre todo si es temporada alta. En esas tres horas, los únicos comercios abiertos son los de los pakistaníes, chinos, turcos o indios; son los únicos que están ofreciendo al público sus servicios, lo que genera un choque cultural entre los autóctonos y los inmigrantes, quienes de alguna forma están 
acostumbrados a horarios y ritmos de trabajo totalmente distintos. Así, se puede comprender el discurso de muchos comerciantes que prefieren contratar a inmigrantes, pues no ponen objeciones a los horarios de trabajo, ya que "cuanto más trabajan, más ganan", a diferencia de los autóctonos, que se limitan a cumplir sus horarios y difícilmente hacen horas extras.

Lo anteriormente expuesto es una de las razones por las que los autóctonos creen que el mercado está encarecido, al ver que estos comercios tienen mayor rendimiento laboral, y no específicamente por el producto que venden:

Bueno, supongo que pagan menos impuestos y también a sus trabajadores les deben de pagar menos, no sé, pero no les deben de pagar por las horas que trabajan [...], porque, claro, ellos vienen y lo necesitan y les dicen "pues 600 euros", a otros les pagaría la ley hasta 800 . Eso sí, conocí a una chica hindú que hace ocho, nueve horas, y le pagan 600 euros al mes; claro, una persona de aquí no, ganaría un poco más.

(Dependienta calle Ferran)

No todos los comentarios hacia los productos que venden suelen ser negativos, también se opina que las demandas comerciales son las que de alguna forma presuponen el tipo de trabajo al que se dedican los inmigrantes.

Las opiniones sobre la llegada de este tipo de comercios al Barrio Gótico difieren entre los comerciantes: mientras que algunos no le dan importancia, otros lo ven como un problema para el resto de los comercios, pues preocupa la imagen que pueden dar del barrio ante el turismo. Lo que está en juego aquí es más bien una cuestión de competencia; así, los comercios de inmigrantes no se ven simplemente como unos comercios cualesquiera, sino como comercios de baja calidad, comercios simples que no incorporan el diseño a su estética ni tienen el aspecto lujoso que se busca para la "recuperación" del centro histórico y la venta de una marca catalana (Aramburu, 2002). Por ello, es de notar que los comerciantes tienen más tendencia a menospreciar el comercio de inmigrantes de origen pakistaní o indio, a diferencia de los comercios multinacionales:

Aquí hay una tienda de incas peruanos, no hay ningún problema, tiene una tienda ahí y tiene otra en otra calle [...]. Entonces hay otro tipo de inmigrantes de origen indio, pakistaní, que le están haciendo mucho daño a lo que es el comercio, porque tú puedes abrir una tienda de tu producto y abres otra tienda de tu producto en la calle de abajo o en la de al lado, lo que no puedes hacer 
es abrir tres tiendas de tu producto en la misma calle, porque lo que haces es empezar a monopolizar el mercado, pero degradas el comercio porque no tienes oferta, además de que esos señores por las razones que sean pueden pagar unos alquileres que los comercios tradicionales no pueden pagar, lo que hace que los alquileres estén por encima de la media y no se puedan pagar [...].

(Comerciante calle Llibreteria)

Las categorías que crea la población de lo que puede o no denominarse inmigrante — en el aspecto comercial—, de los inmigrantes que son "tolerados" y los que no, de los que "hacen las cosas bien" y los que no..., son aquellas que se encuentran dentro de la competencia comercial en el Barrio Gótico, que etiqueta a los inmigrantes como invasores. Sin embargo, de cierta forma sus comercios son aceptados porque brindan, hasta cierto punto, una variabilidad de productos con precios accesibles y horarios más prolongados que los autóctonos no ofrecen, mantienen la vida en el barrio en horarios de descanso e iluminan las calles para que los turistas puedan pasear.

Se habla del manifiesto de una identidad catalana cuya perspectiva se basa en la atracción turística, puesto que un barrio como el Gótico, con el paso del tiempo, ha visto desaparecer la tradicionalidad que representaba para la población que habitaba el mismo barrio, y cuyo desplazamiento se ha visto forzado con la llegada de los nuevos comercios, y no precisamente inmigrantes, sino por las multinacionales, junto con los lugares destinados al ocio y turismo como factores transitorios y no estables, y que poco a poco han ahuyentado a la población residente al convertirse en un lugar poco transitable y lleno de ruido, circunstancias que no brindan un descanso para quien vive ahí y vuelve a casa después de un día lleno de trabajo.

Un mismo producto que no tiene categoría y es turístico, eso para el turista que viene, pero no para el barcelonés, ‘a qué va a venir? ¿A qué va a bajar? Antes podría decir "vamos a comprar hilo", ¿y ahora a qué? ¿Vamos a comprar una camiseta del Barça? Además, el tipo de venta que tienen esos señores se sale de la venta comercial catalana. Salen a la calle a vender y todo regateo, llega un momento que entran a la tienda los turistas y ven que todo es igual.

(Comerciante calle Llibratería) 
Aunque el rechazo al comercio inmigrante aparentemente no fue directo durante el trabajo de campo, constantemente se subrayaban los términos de marginalidad, falta de estética, baja calidad, repetición de las mismas tipologías o exceso de comercios. Pocos ven en el empresariado étnico un fenómeno de impacto positivo en el paisaje funcional, social y formal de Ciutat Vella. Gracias al comercio étnico muchas calles de ese distrito no están abandonadas, las islas privilegiadas ya no son los únicos lugares por donde transitan los turistas (Serra, 2006); como en el caso del Raval, se puede percibir que el comercio inmigrante está contribuyendo a mantener vivo ese modelo de ciudad barcelonés que se ha ido diseñando a lo largo de las últimas décadas.

\section{Conclusiones}

A diferencia de zonas como el Raval, los negocios que se presentan en el Barrio Gótico responden a otro tipo de factores donde el comercio regentado por inmigrantes no solo trabaja con productos dirigidos a sus connacionales específicamente, sino también a públicos más amplios como son el turista y el autóctono. También se debe tomar en cuenta que la transformación comercial que se da en el Barrio Gótico no solo es en el tipo de producto, sino también respecto a las personas que regentan estos negocios. Tal como se aprecia, los negocios siguen manteniendo las carteras de clientes y los productos, cambiando solo el vendedor. Muchos estudiosos del comercio étnico ven a estos nuevos negocios fuera del concepto tradicional del comercio étnico; sin embargo, este fenómeno no está aislado, un ejemplo muy claro es la calle Trafalgar (igualmente en Barcelona), una calle donde estaban establecidas fábricas de mezclilla encabezadas por autóctonos y que actualmente está monopolizada en su mayoría por chinos. Dejo abierta la posibilidad de pensar teóricamente en una nueva definición que no excluya estos comercios, que cuentan con una estructura que está sostenida no solo por un extranjero rico, sino por migrantes que han venido desde lejos para incorporarse a trabajos arduos, duros y que los mantienen casi esclavos.

Actualmente las grandes multinacionales están siendo absorbidas por países que producen en masa, como China, que vende una copia fiel de cada producto que se pueda conocer. Las calles estudiadas permiten comprobar que el Barrio Gótico se encuentra en un proceso de gentrificación comercial donde 
calles como Portaferrissa son acaparadas por cadenas multinacionales que realizan grandes inversiones y compran los edificios más atractivos para utilizarlos como símbolo de la identidad barcelonesa y atraer más compradores. Estos, a su vez, se irán satisfechos por haber comprado ropa y tener una foto en la tienda Zara, pero con la "etiqueta" simbólica de su localización en el Barrio Gótico de Barcelona.

Más allá de la competencia comercial entre los autóctonos, las multinacionales y los inmigrantes, es de vital importancia prestar atención a los procesos de gentrificación que se están viviendo en los centros de las ciudades, que segregan y devalúan el trabajo de la población y que aprovechan fenómenos como la migración para justificar el proceso de cambio, culpando de cualquier problema social a los inmigrantes.

Por ello, conceptualizar la economía étnica como una red espacial compacta no es suficiente, se debe pensar en ella como algo dinámico que muta con el tiempo y que se va adaptando a las necesidades intrínsecas. Se debe pesar en un concepto del comercio étnico como aquel que compite con multinacionales, que invierte, que recibe a cualquier cliente y que aprovecha los intereses turísticos para vender pequeños símbolos de identidad.

\section{Bibliografía}

Aramburu, M. (2008): "Usos y significados del espacios público", Arquitectura, Ciudad y Entorno, año III, núm. 8, pp. 143-150.

- (2002): "Los otros y nosotros. Imágenes del inmigrante en Ciutat Vella de Barcelona”, Ministerio de Educación, Cultura y Deporte, Madrid, p. 281.

- (2005) “Inmigración y usos del espacio público", Los monográficos de B.MM, núm. 6, pp. 35-42.

- (2002):"Los comercios de inmigrantes extranjeros en Barcelona y la recomposición del 'inmigrante' como categoría social”, Scripta Nova, Revista Electrónica de Geografía y Ciencias Sociales, Universidad de Barcelona, <http:// www.ub.edu/geocrit/sn/sn-108.htm>.

Beltrán, J*; Oso, L. y Ribas, N. (2007): Empresariado Étnico en España, Ministerio de Trabajo y Asuntos Sociales y Fundació CIDOB-Observatorio Permanente de la Inmigración, Madrid, pp. 321. 
BorJa, J.(2010): Luces y sombras del urbanismo de Barcelona, Colección de Gestión de la Ciudad, Editorial UOC, Barcelona, p. 363.

Buckley, M. (2007): "Comercios y servicios de los inmigrantes en la Comunidad de Madrid: un enfoque geográfico”, en Beltrán, J;; Oso, L. y Ribas, N. (coords.) (2007): Empresariado Étnico en España, Ministerio de Trabajo y Asuntos Sociales y Fundació CIDOB-Observatorio Permanente de la Inmigración, Madrid, pp. 102-127.

Cócola, A. (2011): "El Barrio Gótico de Barcelona. De símbolo nacional a parque temático", Scripta Nova, Revista Electrónica de Geografía y Ciencias Sociales, Universidad de Barcelona, <http://www.ub.edu/geocrit/sn/sn371.htm >.

Delgado, M.y Malet, D. (2007): “Espacio público como ideología”, Jornadas Marx Siglo XXI, Universidad de la Rioja, Logroño.

Fabre, J.y Huertas, J.M. (1977): Tots els barris de Barcelona, vol. V, L'Eixample i la Barcelona Vella, Edicions 62, Barcelona.

Garcés, A. (2011): “Comercio inmigrante y economías étnicas: síntesis y críticas de los debates vigentes”, Revista Polis, núm. 29, p. 16.

López, P. (1986): El Centro Histórico: Un lugar para el conflicto, Universidad de Barcelona, Barcelona, p. 153.

Monet, N. (2002): La formación del espacio público. Una mirada etnológica sobre el Casc Antic de Barcelona, Barcelona, Catarata.

Moreras, J. (2007): "Iniciativas comerciales inmigrantes en un contexto urbano en transformación: el caso de Ciutat Vella (Barcelona)", en Beltrán, J;; Oso, L.y Ribas, N. (coords.) (2007): Empresariado Étnico en España, Ministerio de Trabajo y Asuntos Sociales y Fundació CIDOB-Observatorio Permanente de la Inmigración, Madrid, pp. 128-154.

Parella, S. (2005): “Estrategias de los comercios étnicos en Barcelona, España”, Política y Cultura, 23: 257-275.

Pujadas, J.J. (2006): “¿Ciudades acogedoras? Transformaciones urbanas, imaginarios y actores sociales", XVI Congreso de Estudios Vascos, pp. 365373.

Ramírez, J.L. (1998): "Los dos significados de la Ciudad o la construcción de la Ciudad como lógica y como retórica", Scripta Nova. Revista Electrónica de Geografía y Ciencias Sociales, Universidad de Barcelona, <http://www. ub.edu/geocrit/sn-27.htm >. 
Robles, J.I. (2008): “Comercio urbano en espacios metropolitanos. Mercados, vidas y barrios", Distribución y Consumo, pp. 19-31.

SÁnchez, A. (coord.) (1994): Barcelona 1888-1929: Modernidad, ambición y conflictos en una Ciudad Soñada, Editorial Alianza, Madrid.

Sargatal, M.A. (2001): "Gentrificación e inmigración en los centros históricos: el caso del barrio del Raval en Barcelona”, Scripta Nova. Revista Electrónica de Geografía y Ciencias Sociales, Universidad de Barcelona, <http:// www.ub.edu/geocrit/sn-94-66.htm>.

Schiappacasse, P. y Müller, B. (2008): "El deterioro urbano en grandes áreas urbanas europeas. Aproximaciones teóricas y metodológicas", Urbano, vol. 11, núm. 18, noviembre-sin mes, Universidad del Bío-Bío, Chile, pp. 82-91.

Serra del Pozo, P. (2005): El comercio étnico en el distrito de Ciutat Vella, Obra Social, Fundación "la Caixa".

Solé, C.; Parella, S. y Cavalcanti, L. (2007): El empresariado inmigrante en España, Colección de Estudios Sociales, núm. 21, Obra Social, Fundación "la Caixa", p. 200.

Subirats, J. y Rius, J. (2004): Del Chino al Raval. Cultura y transformación social en la Barcelona central, Centro de Cultura Contemporánea de Barcelona.

Tabakman, E. (2001): “El Casc Antic de Barcelona: Actuación urbanística o 'limpieza social”, Scripta Nova. Revista Electrónica de Geografía y Ciencias Sociales, <http://www.ub.edu/geocrit/sn-94-67.htm>. 